\title{
NOTAS
}

\section{La relevancia de una mística universitaria. Reflexiones acerca del presente y futuro de la universidad a partir de Klaus Heinrich e Ignacio Ellacuría}

\section{Sebastian Pittl'}

Resumen: El siguiente artículo pone a dialogar las reflexiones del filósofo alemán Klaus Heinrich, sobre el desarrollo de la Universidad Libre de Berlín, con las del filósofo y teólogo vasco-salvadoreño Ignacio Ellacuría (SJ) sobre la Universidad Centroamericana de El Salvador. Se muestra cómo en ambos casos la actualización creativa de intuiciones bíblicas lleva a la recuperación de un saber integral (teórico y práctico, afectivo, crítico y liberador) que hoy puede servir como punto de partida para cuestionar el predominio de un modelo de la universidad neoliberal y de un saber unidimensional.

Palabras clave: Ellacuría, Heinrich, liberación, mística, universidad, universidad neoliberal.

Fecha de recepción: 6 de febrero de 2016 .

Fecha de admisión: 14 de marzo de 2017.

The relevance of a university mysticism. Reflections on the present and the future of the University from Klaus Heinrich and Ignacio Ellacuría (SJ)

Abstract: This article puts into dialogue the reflections of the German philosopher
La pertinence d'un mysticisme universitaire. Réflexions sur le présent et l'avenir de l'université d'après Klaus Heinrich et Ignacio Ellacuría (SJ)

Résumé: L'article met en discussion les réflexions du philosophe allemand Klaus

' Instituto para Iglesia global y misión en la Escuela superior de filosofía y teología Sankt-Georgen en Fráncfort. 
Klaus Heinrich about the "Free University of Berlin" with the reflections about the "Central American University" in San Salvador of the Spanish-Salvadorian philosopher and theologian Ignacio Ellacuría. It shows how both reactualize creatively biblical intuitions to gain an integral concept of "knowing" which is at the same time theoretical and practical, affective, critical and liberating. In the current context this holistic concept can serve as a starting point to criticize the predominance of the neoliberal university and its unidimensional understanding of knowledge.

Key-words: Ignacio Ellacuría, Klaus Heinrich, university and mysticism, university and liberation, neoliberal university.
Heinrich sur le développement de l'Université libre de Berlin et celles du philosophe et théologien vasco-salvadoreño Ignacio Ellacuría sur l'Université centraméricaine du Salvador. L'auteur montre ainsi comment la relecture et la mise à jour créatives des intuitions bibliques conduit à la récupération de connaissances approfondies (un savoir théorique et pratique, affectif, critique et libérateur), qui aujourd'hui peut servir comme point de départ pour contester la domination $d$ 'un modèle néolibéral d'université et d'une connaissance unidimensionnelle.

Mots clé: Ignacio Ellacuría, Klaus Heinrich, université et mystique, université et libération, université néolibérale.

\section{Introducción}

Este artículo ${ }^{2}$ tiene tres partes. Empiezo con algunas observaciones acerca de las transformaciones que se pueden notar en el mundo universitario actual europeo. A partir de ahí discuto algunas ideas sobre la universidad del filósofo alemán Klaus Heinrich. En un tercer paso trato de poner a dialogar esta perspectiva secular y europea con una perspectiva cristiana y latinoamericana que es la de Ignacio Ellacuría, filósofo, teólogo y rector de la Universidad Centroamericana de El Salvador en los años 80 del siglo pasado. Quiero mostrar como Klaus Heinrich e lgnacio Ellacuría, desde contextos diferentes, desarrollan perspectivas muy parecidas que creo que pueden servir de inspiración para la posible o necesaria transformación de la formación académica actual.

El foco de mi contribución está en mostrar como las tradiciones espirituales (en este caso especialmente la tradición judeo-cristiana) pueden ayudar a redescubrir y

2 Publicado originalmente en alemán "Zur Relevanz einer 'universitären Mystik'. Überlegungen zu Gegenwart und Zukunft der Universität im Ausgang von Klaus Heinrich und Ignacio Ellacuría (SJ)", en R. FORNET-BETANCOURT, editor (2015) Tradiciones de formación, espiritualidad y universidad. Hacia una transformación intercultural de la formación académica, Aquisgrán (RFA), 233-244. Una versión más larga aparecerá en S. LASSAK, F. GMAINER-PRANZL y B. WeILER (editores), Theologie der Befreiung auf neven Wegen (en preparación). 
reactualizar la unidad entre el saber y la liberación integral del ser humano que, de alguna manera, es también constitutiva para el proyecto de la ciencia ilustrada occidental.

El artículo se concluye con algunas reflexiones acerca de la relevancia que hoy puede tener una "mística universitaria".

\section{Tendencias actuales: el ejemplo de la Universidad de Viena}

Empiezo con algunas observaciones acerca de las transformaciones en el mundo universitario actuales. Una gran parte de estas transformaciones está relacionada con la imposición de un modelo neoliberal en la educación y la ciencia que produce efectos similares desde Chile hasta Corea del Sur. ${ }^{3}$ Sin entrar en muchos detalles creo que la característica más significativa de este cambio en Europa consiste en que la idea de un saber que no está buscado por otros fines, sino que es considerado como un fin en sí mismo, está desapareciendo paulatinamente. Esta idea constituye un legado de la filosofía griega que ha influido mucho en el desarrollo occidental del saber y de la universidad. Ha sido el motivo central para defender la libertad de la ciencia ante la política, la economía y la iglesia y ha sido la razón fundamental para darles cierta autonomía a las universidades dentro de las estructuras políticas y estatales.

Hoy esta idea pierde credibilidad ante la reclamación de una utilidad del saber de carácter político, social y sobre todo, económico. Se podrían dar muchos ejemplos que reflejan esa tendencia, desde la implantación de estructuras jerárquicas y eficaces de gestión hasta la creciente presión de atraer fondos ajenos y colaborar con la empresa privada. El más llamativo es quizá la terminología economicista que invade el lenguaje en los planes de desarrollo de las universidades. Para dar un ejemplo de mi contexto específico, en el plan de desarrollo actual de la Universidad de Viena, que como universidad más grande y antigua del mundo de habla alemán actual es un ejemplo representativo, se lee:

La Universidad de Viena trata de mejorar su posición competitiva respecto de las universidades de investigación a nivel nacional e internacional y exige a la política a que le ayude en este proceso. ${ }^{4}$

${ }^{3}$ Cf. los análisis de los distintos contextos en R. FORNET-BETANCOURT (2015) op. cit.

${ }^{4} \mathrm{Cf}$. el plan de desarrollo de la Universidad de Viena 2020, 14. El documento es disponible online en: 
La contribución a la mejora de la posición de la economía austriaca en el mercado global es considerada por la universidad como manera esencial de cumplir con su responsabilidad social. ${ }^{5} \mathrm{Si}$ se toma la frecuencia de los términos utilizados como un criterio al menos indirecto del cambio ideológico llama la atención la posición dominante que adquiere el término "competencia". En la parte general del documento el término aparece treinta y cuatro veces, mientras que el término "crítica" solamente se encuentra tres veces, "reflexión/reflexionar" cuatro veces, "libertad" y "justicia" una vez, y "verdad", "derechos humanos" y "poder" ninguna. Para mostrar la radicalidad y profundidad del cambio ideológico que se refleja en este cambio semántico me gustaría citar del plan de desarrollo de la misma universidad de 1999, donde se lee:

La Universidad de Viena considera su posición en el centro geográfico de Europa como chance y tarea y se compromete a reflexionar de una manera crítica y autocrítica sobre la relación entre política, poder y ciencia. Además la universidad se compromete a defender los principios democráticos dentro y fuera de sí misma, a desarrollar más los derechos humanos y ciudadanos y a contribuir a la realización de esos derechos en la sociedad, a superar barreras nacionales, religiosas y culturales y a contribuir al diálogo de culturas, pueblos y religiones. ${ }^{6}$

Estas frases expresan una fuerte conciencia de la responsabilidad que surge en el contexto de la realidad geográfica, social e histórica de la universidad, una conciencia de la implicación mutua entre ciencia, política y poder y un compromiso claro con la promoción de los derechos humanos y ciudadanos, la democratización de la sociedad y el diálogo entre culturas, pueblos y religiones. En el plan de desarrollo actual estos temas casi desaparecen por completo.

Muchos académicos críticos en Europa interpretan la creciente tendencia economicista de la universidad y la ciencia como una traición a la idea de la universidad "humboldtiana", que durante los últimos dos siglos representaba el ideal de la universidad europea, o al menos alemana. Yo creo que más que de una traición, se trata de la perversión de una reclamación en principio legítima, a saber, que la ciencia y la universidad deben servir a la vida humana. Ahora bien, con eso no quiero decir que la ciencia y las universidades deben someterse acríticamen-

http://www.univie.ac.at/fileadmin/user_upload/startseite/Dokumente/Entwicklungsplan2020_de.pdf (último acceso: 30-I-2016).

${ }^{5}$ Cf. ibid., 11.

${ }^{6}$ El documento es disponible online en: http://www.uv.ruhr-uni-bochum.de/leitbild/leitbild/Leitbildwien.htm (último acceso: 30-I-2016). 
te a las demandas del mercado ni que la ciencia y la universidad no deberían gozar de una cierta autonomía respecto de una praxis inmediatista, pero sí que deben responder, conforme a su propia manera académica, a la exigencia de una liberación integral, tanto política como social, tanto religiosa como cultural del hombre concreto. Yo creo que solamente por haberse alejado de este servicio a la libertad y la vida se ha podido producir ese tipo de saber académico estéril y elitista (al menos en algunos sectores de la universidad occidental) que ahora sirve a los actuales reformistas de la universidad como legitimación para llevar a cabo la opción económica neoliberal de la ciencia bajo el pretexto de promover una utilidad concreta del saber.

Creo que en este punto el diálogo con las grandes tradiciones espirituales de la humanidad puede servir de inspiración para la universidad y la ciencia ya que casi todas ellas conocen un tipo de saber que une a la vez dimensiones noéticas, éticas, estéticas y prácticas. Eso al menos es muy claro en la tradición judeo-cristiana. Solamente menciono estos ejemplos: La Biblia utiliza la misma palabra עד (jāda') para referirse al acto de "conocer" y al acto de hacer el amor (cf. Gen 4,1: Conoció Adán a su mujer Eva, y concibió y dio a luz a Caín) lo que expresa la sensualidad y afectividad del conocer bíblico. En Jeremías, por otra parte, encontramos la unidad entre conocer a YHWH y hacer la justicia cuando YHWH recrimina al rey Zidkijah:

¿Piensas que eres rey porque compites en obras de cedro? Si tu padre comió y bebió y le fue bien, es porque practicó la justicia y el derecho. Hizo justicia a pobres e indigentes, por eso le fue bien. ¿̇No fue eso conocerme a mí? (Jer 22,15-16).

Igualmente en la primera carta de Juan se lee: El que no ama, no conoció a Dios, porque Dios es amor (1 Jn 4,8). La unidad de aspectos noéticos, éticos, afectivos y prácticos aparece aquí claramente.

En la historia de la cristiandad la riqueza del conocer bíblico se desvaneció en favor de la dominancia de un conocer puramente teórico cuya unidimensionalidad aumentó aún más en la medida que perdió incluso las dimensiones de "contemplación" que fueron características de la $\theta \varepsilon \omega p i ́ a$ ("theoria") griega. ${ }^{7}$ Partiendo de un concepto del conocer tan empobrecido, la idea de una ciencia como un fin en sí mismo se convierte en una abstracción anémica.

Con eso no pretendo reemplazar la idea de un saber que es buscado solamente por sí mismo. Como ideal regulativo eso me parece una idea valiosa e importante. Pero sí creo que es necesario complementar eso con un tipo de saber más integral

\footnotetext{
${ }^{7}$ La palabra griega $\theta \varepsilon \omega$ pía hace referencia al acto de ver/mirar.
} 
como el que encontramos en las tradiciones espirituales. Creo que este tipo de saber puede servir para redescubrir las dimensiones negadas $v$ oprimidas de este saber teórico y desenmascarar su uso ideologizado. De hecho ya la famosa "theoria" de Aristóteles no fue tan autosuficiente como el mismo Aristóteles pretendía ya que fue el privilegio de unos pocos hombres libres cuyo ocio fue posibilitado por la labor de los esclavos. El conocer bíblico a este respecto representa un conocer mucho más democrático e igualitario.

Ahora bien, por mi experiencia como teólogo en una universidad pública y secular sé muy bien que en la universidad secularizada europea es casi imposible reactualizar estas intuiciones de la tradición judeocristiana de una manera inmediata. Son demasiado grandes las reservas y sospechas ante una presencia activa de "lo religioso" en la universidad que se nutren parcialmente (y con cierta razón) del hecho de que la libertad académica en Europa solamente se logró por una lucha que tuvo que dirigirse también contra los intentos de monopolización y sumisión del saber por las autoridades eclesiales.

Así, en lo que sigue, quiero dar un pequeño rodeo. Eso me lleva a las reflexiones sobre la universidad de Klaus Heinrich que, desde un horizonte secular y con referencia a la situación de la Universidad Libre de Berlín, desarrolla perspectivas que se corresponden de alguna manera con las mencionadas intuiciones bíblicas. A partir de ahí creo que se hacen visibles posibilidades para una fértil contribución de las tradiciones espirituales para la transformación de la formación académica actual que quiero explicitar en la última parte en diálogo con algunas ideas de lgnacio Ellacuría.

\section{2. “Verdad - Justicia - Libertad". ${ }^{8}$ Klaus Heinrich y la historia de la Universidad Libre de Berlín}

La historia de la Universidad Libre de Berlín refleja y simboliza de manera especial el contexto específico de la universidad europea en la segunda mitad del siglo veinte. La fundación de esta universidad se debe a la iniciativa de estudiantes que después del fracaso moral de la universidad nacionalsocialista y ante la incipiente estalinización de la universidad en la Alemania oriental pretendían una universidad verdaderamente libre. Klaus Heinrich fue uno de estos estudiantes y, más tarde, profesor de esta misma universidad. Sus discursos sobre la universidad reflejan

8 "Verdad - Justicia - Libertad" es el lema de la Universidad Libre de Berlín. 
con creciente escepticismo la pretensión originaria, la traición a esta pretensión y finalmente lo que Heinrich considera el fracaso de esta universidad. Enumero solamente algunas de sus ideas especialmente interesantes para nuestro tema: ${ }^{9}$

1. Según Heinrich la incapacidad de la universidad alemana de resistir a su instrumentalización por parte de la ideología nacionalsocialista había desenmascarado definitivamente la pretensión de una universidad apolítica como una ilusión ingenua y peligrosa. La universidad supuestamente "apolítica" se habría mostrado como idéntica a la universidad politizada. Por eso, según Heinrich, la ideologización de la universidad no puede ser evitada por la (imposible) exclusión total de lo político, sino solamente si la universidad asume su constitutivo carácter público y político de una manera consciente y crítica. La manera más propia de asumir ese reto es la tarea de "darle a la sociedad una conciencia de sí misma"10. Para cumplir esta misión la universidad debe contextualizarse radicalmente, esforzarse para descubrir las preguntas fundamentales de la sociedad, "traducir"11 estas preguntas en preguntas científicas y comunicar los resultados de su investigación con la sociedad de una manera dialógica.

2. El horizonte último de la ciencia y la universidad para Heinrich no puede ser otro que la liberación integral o la "felicidad" del hombre. ${ }^{12}$ No sería posible una verdadera libertad académica sin la libertad de la sociedad. Ambas son inseparables, en el fondo son la "misma". Heinrich recuerda que esa conexión entre la libertad de la ciencia y la liberación integral del hombre ha sido constitutiva para toda la tradición de la ciencia ilustrada, desde Leibniz y Kant hasta Humboldt. ${ }^{13}$ Según Heinrich el gran prestigio del que goza la ciencia en occidente no se debería tanto a logros o descubrimientos específicos sino a esa pretensión emancipadora. Si la ciencia abandonara esta pretensión emancipadora perdería su sentido, se

\footnotetext{
${ }^{9}$ Todas las citas de Klaus Heinrich están tomadas de tres discursos suyos ("Erinnerungen an das Problem einer freien Universität" (1967); "Widerspruch und Verantwortung in der Hochschule" (1970); sowie: "Zur Geistlosigkeit der Universität heute" (1987) que posteriormente fueron publicadas en el libro: Klaus Heinrich, der gesellschaft ein bewußtsein ihrer selbst zu geben, Frankfurt am Main/Basel 1998. Los números de página siguientes se refieren a esta edición.

${ }^{10}$ Este también es el título del libro con los discursos de Heinrich: Der gesellschaft ein bewußtsein ihrer selbst zu geben. Véase la nota 8.

${ }^{11} \mathrm{CF}$. HEINRICH, Widerspruch, 45 .

${ }^{12} \mathrm{CF}$. HEINRICH, Erinnerungen, 19.

${ }^{13} \mathrm{CF}$. HeINRICH, Widerspruch, 34
} 
volvería cínica, incluso diabólica y se convertiría en el ayudante organizativo y racionalizante de conflictos destructivos globales. ${ }^{14}$

3. Una ciencia crítica para Heinrich además necesita recuperar las dimensiones que una visión reduccionista de la racionalidad oprime o excluye de sí misma. Así todo el ámbito de lo afectivo e "irracional" (afecciones, pulsiones, etc.) debería ser reintegrado de una manera adecuada. Recuerda Heinrich que en el núcleo de la ciencia ilustrada no radica una razón fría, racionalista, sino la pasión profunda por la liberación del hombre por medio del saber y la crítica. Además debería tenerse en cuenta que el "espíritu" que movió la filosofía occidental desde Jakob Böhme y Hegel hasta hoy día tiene una de sus raíces más profundas en la rûah (חור) veterotestamentaria que se refería originariamente a una pulsión sensual. ${ }^{15}$

Sin embargo, con los años, la perspectiva de Heinrich respecto del desarrollo real de la Universidad Libre de Berlín se volvió cada vez más pesimista. Terminó opinando que una creciente tecnocratización y burocratización había separado a la universidad de los problemas concretos de la sociedad y había traicionado la visión utópica que tenían sus fundadores. El fracaso del proyecto utópico de una "universidad distinta" en Berlín simbolizaba para Heinrich el fracaso de la universidad europea en general. De la misma manera que las grandes revoluciones habrían fracasado por la contradicción entre la universalidad de su pretensión y la imposición de un interés particular, el interés de la clase victoriosa, ${ }^{16}$ también las grandes utopías universitarias habrían fracasado por la perversión de las reclamaciones emancipatorias de la razón ilustrada en un formalismo del conocer, producir y dominar. ${ }^{17}$ La universidad occidental según Heinrich no solamente no ha logrado contribuir a la abolición de estas contradicciones, sino que incluso las ha legitimado y apoyado al otorgar aura de racionalidad a la explotación de la naturaleza y pueblos enteros. Con eso, la universidad europea se habría traicionada a sí misma, porque la libertad de los hombres según Heinrich no puede ser dividida en la libertad de unos pocos y la esclavitud de la mayoría. Solamente la universalidad de su pretensión emancipadora (y no una supuesta unidad de los

\footnotetext{
${ }^{14} \mathrm{Cf}$. HEINRICH, Widerspruch, 47.

${ }^{15} \mathrm{Cf}$. HeINRICH, Geistlosigkeit, 72. Otra raíz del "espíritu" occidental es sin duda el voũs ("nous")

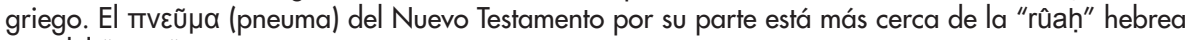
que del "nous".

${ }^{16} \mathrm{CF}$. HEINRICH, Widerspruch, 36.

${ }^{17}$ Cf. ibid.
} 
saberes abstracta) legitima para Heinrich el uso singular de los términos ciencia y universidad. Así la unidad del género humano representaría para la universidad hoy el único singular aún vigente. ${ }^{18}$

Es interesante notar que Heinrich excluye de su juicio sobre el fracaso de la universidad (quizá de una manera un poco simplista) a las universidades del así llamado "tercer mundo". En algunas de ellas la perspectiva emancipadora aún no habría sido reemplazada por el bullicio desorientado que dirigiría hoy las universidades occidentales, así que de alguna manera hoy estas universidades representarían y continuarían el impulso utópico-liberador del proyecto de la ciencia ilustrada que ha sido traicionado en el Occidente.

\section{Una universidad "para el cambio social". 19 Ignacio Ellacuría y la UCA de EI Salvador}

Lo que dice Heinrich acerca de la universidad en el tercer mundo me permite acercarme, en un tercer paso, a las reflexiones de Ignacio Ellacuría y al proyecto de una universidad "para el cambio social" que quiere ser la Universidad Centroamericana José Simeón Cañas (UCA) de los jesuitas en San Salvador. A pesar de tratarse de un contexto totalmente diferente, las reflexiones de Ellacuría y la historia de la UCA de El Salvador, comparten muchas similitudes con las ideas de Heinrich y la historia de la Universidad Libre de Berlín.

La UCA fue fundada en 1965, 17 años después de la Universidad Libre de Berlín. Sobre todo bajo el rectorado de Ellacuría, desarrolló la explícita comprensión de sí misma como una institución académica cuya función fundamental había de ser contribuir a la liberación integral de las mayorías empobrecidas, marginadas y explotadas de El Salvador. Esta perspectiva en el caso de Ellacuría y la UCA se nutre claramente de una inspiración cristiana e ignaciana. Sin embargo, el mismo Ellacuría trató de traducir esta inspiración espiritual en una argumentación filosófica que puede estudiarse en una colección de textos publicada en $1999 .{ }^{20}$ Los textos

${ }^{18} \mathrm{CF}$. HEINRICH, Geistlosigkeit, 85.

${ }^{19}$ Así reza el lema de la Universidad Centroamericana de El Salvador.

${ }^{20} \mathrm{CF}$. Ignacio ElLACURía (1999) Escritos universitarios, San Salvador. Los textos y discursos de esta colección datan de los años 1971-1989. Los números de página en las siguientes notas se refieren a esta edición. 
y discursos aquí recopilados tratan temas muy variados, desde la arquitectura de una universidad latinoamericana (que según Ellacuría no debería tratar de imitar la apariencia de una universidad norteamericana sino responder a la realidad histórica que le rodea) hasta el currículum, la financiación, los sueldos de los profesores etc. Éstas son algunas ideas claves.

1. Como para Heinrich también para Ellacuría toda universidad, por estar insertada en un contexto histórico y social concreto, tiene necesariamente una dimensión política que debe asumir críticamente para que no se convierta en una fuente de ideologización. Ahora bien, ejercer esta dimensión política para Ellacuría no significa que la universidad deba convertirse en un partido político. Con eso perdería su dimensión académica y consecuentemente también lo específico que puede aportar para el cambio social. La manera adecuada de actuar políticamente de la universidad para Ellacuría pasa por la cultura como su campo específico, por la palabra eficaz como método y por la transformación de las circunstancias de vida de las mayorías empobrecidas como horizonte. ${ }^{21}$

2. Según Ellacuría una universidad asume su carácter político de una manera adecuada cuando entre sus tres funciones constitutivas, que serían la docencia, la investigación y la proyección social, da prioridad a esta última. Esta prioridad de la proyección social no tiene por qué perjudicar a la docencia y a la investigación porque, según Ellacuría, tanto la docencia como la investigación se volverían más sinceras, profundas y creativas si se dejasen inspirar por las exigencias de un contexto histórico social concreto. Estas exigencias para Ellacuría encuentran a su vez su criterio en la opción por los pobres. Dar prioridad a la proyección social según la opción por los pobres significaría entonces configurar toda la labor universitaria desde sus necesidades y liberando el mayor potencial posible para la proyección social formalmente tal. ${ }^{22}$ Ésto, para Ellacuría, supone entre otras cosas

una gran austeridad en la obra física y en el equipamiento universitario [...] así como en todo lo que sea proyección de imagen externa, que debe estar en la mayor coherencia posible con lo que son las mayorías y con lo que es el estilo de vida del país [...], supone [...] una selección estricta del personal según un máximo de capacidad, de laboriosidad y de identificación con la causa popular [...], supone [...] un enfoque de la docencia hacia la preparación de posibles agentes de cambio social [...] y un enfoque de la investigación [...] hacia lo que más ayudaría, tanto en el orden técnico como en el orden

\footnotetext{
${ }^{21}$ Ignacio Ellacuría, "Diez años después, ¿̇es posible una universidad distinta?" (1975), 54-67.

${ }^{22}$ Ignacio Ellacuría, "Universidad y políitica" (1980), 197.
} 
social, cultural, y político para que las mayorías lleguen a alcanzar una vida humana digna y una participación real en los bienes, recursos y dirección del país. ${ }^{23}$

3. Es importante resaltar que para Ellacuría la opción de la universidad por las mayorías empobrecidas no sólo está motivada por motivos éticos sino también por motivos epistemológicos. En las mayorías empobrecidas se mostraría con claridad lo que el sistema político y social dominante tiene que excluir y oprimir para poder presentarse como el más racional. Por eso, elegir a las mayorías empobrecidas como lugar epistemológico privilegiado no constituye para Ellacuría un "capricho", sino una decisión muy racional para acceder a la verdad de lo que está pasando en la sociedad: las mayorías y su realidad objetiva [constituyen] el lugar adecuado para apreciar la verdad o falsedad del sistema en cuestión. ${ }^{24}$

4. Precisamente esa opción por las mayorías empobrecidas constituye para Ellacuría la característica específica de una universidad cristiana. El cristianismo de la universidad según Ellacuría

no debe medirse (en un principio) ni desde profesiones de la fe, ni desde acatamientos jerárquicos, ni desde la enseñanza explícita de temas religiosos, [....] sino desde su orientación histórica ${ }^{25}$

que, en el fondo, no podría ser otra que la del reino de Dios proclamado por Jesús:

Una universidad de inspiración cristiana lo será tanto más cuanto más contribuya a que se vaya haciendo realidad esa utopía anunciada y prometida por Jesús, que es el reino de Dios. ${ }^{26}$

Solamente

una universidad cuyo horizonte es el pueblo de los más necesitados, que exigen su propia liberación y luchan por ella; cuyo compromiso fundamental es el cambio de estructuras y de personas, en orden a una creciente solidaridad; cuyo talante es la lucha arriesgada a favor de la justicia; cuya inspiración en el juicio ético de las situaciones y de las solu-

\footnotetext{
${ }^{23}$ Ibid., 197-198.

${ }^{24} \mathrm{lbid}$., 195. Eso para Ellacuría no significa que el lugar de las mayorías empobrecidas sea un lugar sin ideologización. Sin embargo, por carecer de posibilidades de imponer su punto de vista a otros sectores de la sociedad, el grado de ideologización en las mayorías empobrecidas para Ellacuría es menor que en otros sectores.

${ }^{25}$ Ellacuría, "Diez años después", 92.

${ }^{26}$ ElLACURÍA, "La inspiración cristiana de la UCA en la docencia" (1989), 290.
} 
ciones, así como de los medios que han de llevar desde las situaciones a las soluciones, es la del evangelio, es una universidad cristiana. ${ }^{27}$

\section{A modo de conclusión: sobre la necesidad y el significado de una "mística universitaria"}

Las reflexiones de Ellacuría acerca de la universidad latinoamericana se nutren claramente en las fuentes espirituales de la tradición cristiana e ignaciana sin por eso llegar a una sumisión teocrática del saber y de la universidad o a una destrucción de su autonomía que tanto teme la universidad occidental cuando se habla de la presencia de la religión en el mundo académico. Quizá precisamente por eso la perspectiva de Ellacuría logra recuperar dos cosas que siguiendo a Heinrich ha perdido la universidad occidental: la clara perspectiva emancipadora y la perspectiva universal que resiste la tentación de hacer de la universidad un instrumento de la lucha de las economías nacionales en la competencia del mercado neoliberal. Ellacuría subraya explícitamente la "utilidad" social del saber, pero no en un sentido utilitarista o economista sino respecto del acompañamiento reflexivo de una praxis liberadora.

El filósofo norteamericano David Gandolfo ha indicado-y creo que con razón-que el sistema universitario occidental actual y su estructura motivacional están en una contradicción fundamental con esta perspectiva. ${ }^{28}$ Pero aunque sea improbable que el sistema universitario como tal o universidades completas asuman hoy esta perspectiva, creo que sí es posible que académicos individuales formen grupos informales para llevar esta perspectiva emancipadora adelante. Gandolfo cualificó

${ }^{27}$ Ignacio EllacuríA, "Diez años después, ¿̇es posible una universidad distinta?" (1975), 92.

${ }^{28}$ Cf. David I. GANDOLFO (2014) "A Different Kind of University Within the University. Ellacuría's Model in the Context of the United States", en J. M. AshleY, K. BuRKE y R. CARDenAl, editores (2014) A Grammar of Justice. The Legacy of Ignacio Ellacuría, Maryknoll, Nueva York, Orbis, 161-172:

The hyper-precarious, hyper-competitive academic job market and the organization of that model around national searches combine to produce intellectuals who are forced to engage in endless self-promotion for at least the first decade of their professional lives [...] and who, at the same time, have little connection to or knowledge of the communities where they teach and do research. [...] This is a huge structural impediment to forging an academy that is engaged in and relevant to the problems of oppressed people; it raises another difficult question [...]: should being anchored in the historical reality in which one conducts one's professional life be some part of the criteria used at the different university for hiring, tenure, and promotion? 
a estos grupos como una universidad distinta dentro de la universidad como dice explícitamente el artículo citado de D. I. Gandolfo. En la misma línea Heinrich, recurriendo al motivo teológico de la "ecclesia invisibilis", hablaba de la posibilidad de una "universitas invisibilis". ${ }^{29}$ Ellacuría, quien fue mucho más optimista respecto de las posibilidades de realizar una universidad al servicio de los pobres, también institucionalmente subrayó la necesidad de una mística universitaria. ${ }^{30}$ Esta mística sería la "mística" de "aquellos que estén convencidos de que su autorrealización personal pasa por el compromiso constante y efectivo con los más necesitados", ${ }^{31}$ que consideren su formación académica no como un estatus sino una responsabilidad, que perciban la profunda unidad que existe entre verdad, justicia y libertad y que estén dispuestos a arriesgarse para defender esta verdad que libera (cf. Jn 8,32 ) hasta el punto de poner en riesgo su propia vida.

Ellacuría no habla de una mística cristiana sino de una mística universitaria para incluir también a todas las personas de buena voluntad dispuestas a unirse a esta perspectiva. Sin embargo la inspiración cristiana e ignaciana en estas reflexiones está muy clara. Que una inspiración así puede contribuir de forma importante o que incluso sea necesaria para construir una universidad distinta, liberadora e intercultural lo muestra claramente el ejemplo del propio Ellacuría, quién pagó el precio por su compromiso existencial y académico con su propia vida. Que haya una muerte que no sea fracaso sino inspiración y fuente de nueva vida es también algo que se puede aprender de la tradición cristiana y de lo cual deberían dar testimonio todos los que quieren seguir en la línea de Ignacio Ellacuría hoy.

\footnotetext{
${ }^{29} \mathrm{Cf}$. HeINRICH, Geistlosigkeit, 86.

${ }^{30}$ Cf. ElLACURÍA, "Los retos del país a la UCA en su vigésimo aniversario" (1989), 269.

${ }^{31}$ Ibid.
} 